\title{
BIBLIOTECA DE EXPERIMENTOS COMO PROPOSTA DE LABORATÓRIO DE MECÂNICA NO FORMATO EAD
}

\author{
SÃO JOSÉ DOS CAMPOS/SP JULHO/2018
}

\author{
Douglas Carlos Vilela - ITA - douglascarlosvilela@gmail.com \\ José Silvério Edmundo Germano - ITA - silverio@ita.br
}

Tipo: Relato de Experiência Inovadora (EI)

Categoria: Métodos e Tecnologias

Setor Educacional: EDUCAÇÃO SUPERIOR

\begin{abstract}
RESUMO
O projeto denominado biblioteca de experimentos foi um piloto utilizado no laboratório de física do ITA - Instituto tecnológico de Aeronáutica. Este piloto foi parte das atividades no laboratório de mecânica do ITA. Ele foi realizado no $1^{\circ}$ semestre de 2018 com 20 alunos do $2^{\circ}$ ano de engenharia. $O$ principal objetivo é verificar uma forma de expandir as atividades do laboratório de física uma vez que o ITA passará por expansão dos seus estudantes em 2020. O projeto consistiu no desenvolvimento de 30 maletas contendo o material para os estudantes realizarem práticas experimentais de oscilações e ondas. Como material de apoio para a construção dos experimentos, foi criado um conjunto de tutoriais que foram disponibilizados no Google Classroom. Este ambiente serviu de ferramenta de gestão do processo ensino e aprendizagem. Durante um mês acompanhamos o desenvolvimento dos experimentos dos estudantes, comunicando por fórum ou e-mail. Como resultado das atividades experimentais, os alunos produziram simulações virtuais, vídeos explicativos e relatórios mostrando $o$ desenvolvimento dos experimentos. No final deste processo, os alunos responderam um questionário avaliando a proposta da biblioteca de experimentos apontando os pontos positivos e as carências a serem aperfeiçoadas. Temos convicção que os trabalhos com uso das tecnologias digitais podem tornar o processo de ensino e aprendizagem ainda mais atrativo, eficiente e engajador.
\end{abstract}

Palavras-chave: Laboratório de Física, oscilações, ondas, biblioteca de experimentos

\section{AGRADECIMENTOS}

AGRADECEMOS A CAPES E AO ITAEX PELO APOIO FINANCEIRO PARA REALIZAÇÃO DESSE PROJETO.

AGRADECEMOS A COLABORAÇÃO DAS ALUNAS DE PÓS-GRADUAÇÃO CARLA CURSINO E FLÁVIA ROCHA E OS TÉCNICOS DO LABORATÓRIO. 


\section{Introdução}

Não é de hoje que muito se fala sobre o momento de transformação da escola e da educação no país. Novas metodologias, novas técnicas, novas tecnologias surgem a cada dia com um objetivo maior de formação, seja ela em educação infantil, fundamental, médio ou superior.

Em especial na graduação, com foco no ensino da engenharia, o Instituto Tecnológico de Aeronáutica (ITA), vem se movimentando para modernizar sua metodologia de ensino, buscando mudanças na formação de novos engenheiros e seus professores.

Nos últimos anos, como parte integrante do curso FIS14 e FIS26 ministrado pelo departamento de física no curso fundamental do ITA, foram desenvolvidos pelos alunos que estavam no $1^{\circ}$ e $2^{\circ}$ ano fundamental diversos projetos de elaboração a partir do conceito PBL (Project Based Learning) dos experimentos de física sob coordenação do proponente do projeto Prof. Dr. José Silvério Edmundo Germano.

Os vídeos explicativos desses projetos podem ser assistidos e acompanhados no canal criado no Youtube (https://www.youtube.com/watch?v=wcOq|xU4|4M\&).

Do ponto de vista acadêmico, essa iniciativa propiciou aos alunos que estão nos primeiros anos de engenharia a possibilidade de se envolverem no desenvolvimento de experimentos desafiantes e motivantes, possibilitando dessa forma explorar outras habilidades e competências dos nossos alunos como:

- Construção de experimentos com instrumentos de baixo custo;

- Pequenas usinagens com ferramentas disponíveis no laboratório;

- Impressão de objetos com a impressora 3D;

- Utilização de sensores como forma de aquisição de dados;

- Construção de relatório através de vídeo.

Essas habilidades e competências vão ao encontro com as novas demandas exigidas no mercado de trabalho e também com o uso de novas tecnologias no ensino de ciências. 
Moreira (2009) aponta que atualmente o ensino da Física tornou-se desatualizado, tanto em termos de conteúdo quanto de tecnologias, focado no treinamento para as provas e abordando a Física como uma ciência acabada, tal como apresentada em um livro de texto. Tal ênfase resulta em um ensino centrado no docente, não no aluno, e, muitas vezes, vazio de significado para a sua formação. O autor ainda aponta que dificilmente são incorporadas as TDIC (Tecnologias Digitais da Informação e Comunicação) fazendo uso de situações que não trazem sentido para os alunos, ou seja, não buscam uma aprendizagem significativa crítica.

Apoiados em (Moreira e Gonçalves, 1980; Batista at al., 2009), eles destacam a importância do ensino experimental, em suas diversas etapas, principalmente no caso da Física, que é uma ciência essencialmente experimental. Apontam ainda que a atividade prática é fundamental no processo de formação, pois é no laboratório que o aluno comprovará os modelos teóricos visto em sala de aula Laudares et al (2014) diz que apesar da importância da atividade experimental para a aprendizagem dos conceitos físicos, o que se observa é uma certa passividade dos alunos em relação às práticas em laboratório. Segundo ele, tal fato pode estar relacionado com:

"a utilização de procedimentos experimentais que utilizam kits pré-fabricados, que muitas vezes operam como verdadeiras caixas-pretas. Por ser hermético, quase não há a possibilidade de realizar medidas diferentes daqueles para os quais foram projetadas (Aguiar e Laudares, 2001), fazendo com que o aluno desenvolva apenas alguns critérios adotados no processo científico". (Laudares et al, 2014, p. 02)

Outro motivo que pode levar ao desinteresse do aluno é a defasagem estrutural dos equipamentos utilizados nos laboratórios. Para sanar esta defasagem, Laudares (et al, 2014) aponta vários autores, como, Cavalcante e Tavolaro, 2000, Aguiar e Laudares, 2001, que apresentam sugestões para a instrumentalização do laboratório.

Dentre as diversas ações sugeridas, o autor aponta a inclusão de novas tecnologias, justificando que essa opção pode "diminuir os custos na realização de experiências". (Laudares et al, 2014)

Com base nisso, desenvolveu-se no ITA um projeto piloto denominado "Biblioteca de Experimentos". Esta proposta vai ao encontro das práticas encontradas no ensino EAD uma vez que trabalha com a premissa dos estudantes retirar uma maleta contendo material suficiente para realizar os experimentos em suas residências.

A seguir descreveremos esse projeto, seu desenvolvimento e aplicação com os alunos. 
Ao final discutiremos os resultados apresentados durante o processo, salientando que este continua em desenvolvimento no momento de entrega deste artigo.

\section{O Projeto Piloto: Biblioteca de Experimentos}

Baseado nas argumentações acima, a proposta desse projeto tem como objetivo central construir uma biblioteca de experimentos no formato EAD - Ensino à Distância para dar suporte ao processo de expansão do laboratório de física dado o aumento do número de alunos previsto para 2019.

Essa biblioteca será montada com três frentes de atuação como nos mostra a figura 1.

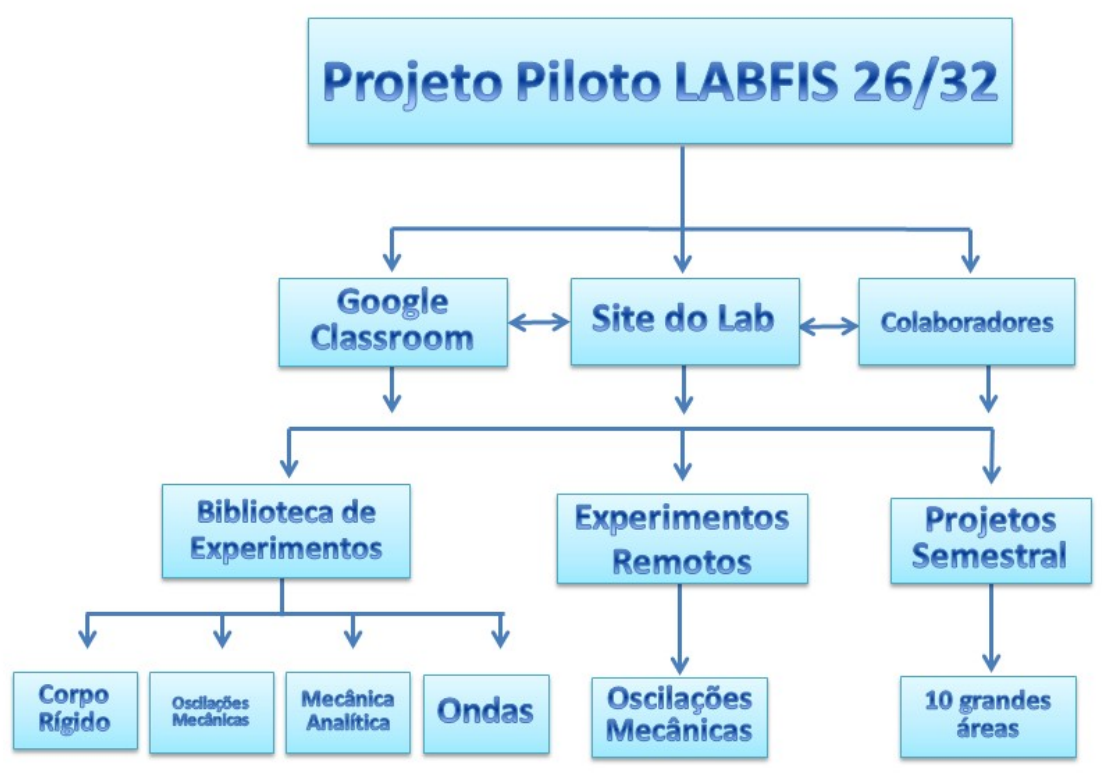

Figura 1 - Fluxograma do Projeto Piloto do Laboratório de Física do ITA. Fonte: O autor

\subsection{Google Classroom}

A aplicação de atividades de laboratório tem como pressuposto ações para os alunos realizarem e, na maioria das vezes, um relatório para ser gerado. A pergunta que fazemos é: Quando o aluno acessa um experimento remoto, como ele deve realizar esse relatório? Qual melhor formato? Como interagir com o mesmo?

Diante disso, criamos uma sequência didática na plataforma Google Classroom. Esta plataforma existe desde 2012 e vêm sendo aprimorada e incorporada em escolas e 
universidades do mundo como uma TIC - Tecnologia de Informação e Comunicação entre professores e alunos.

Alguns resultados recentes mostram que aplicações do Google Classroom em sala de aula tem uma efetividade relativamente alta, na medida que há internet e smartphones com mais qualidade e acessibilidade[1].

Com isso, mostraremos adiante o formato da página previamente montada para gerenciar as atividades do curso.

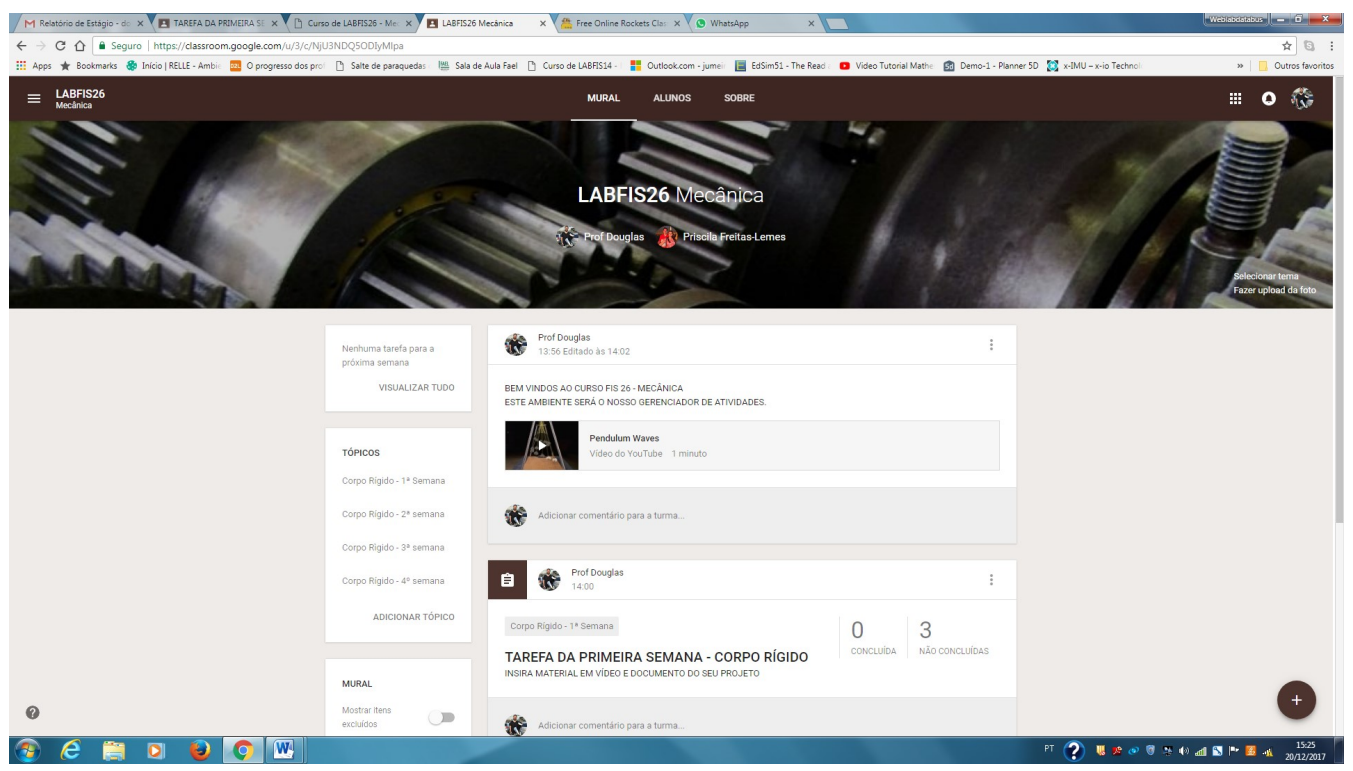

Figura 2 - Página de gerenciamento das atividades do Laboratório na plataforma Google Classroom. Fonte: O autor

\subsection{Site do LAB}

Do ponto de vista de material de apoio como apostilas com conteúdo teórico, vídeos, artigos de experimentos e métodos experimentais estão contemplados num site (www.fis.ita.br/fis26).

[1] Acesso 20-04-18

https://teachingforward.net/improved-teacher-experience-with-google-classroom/ 


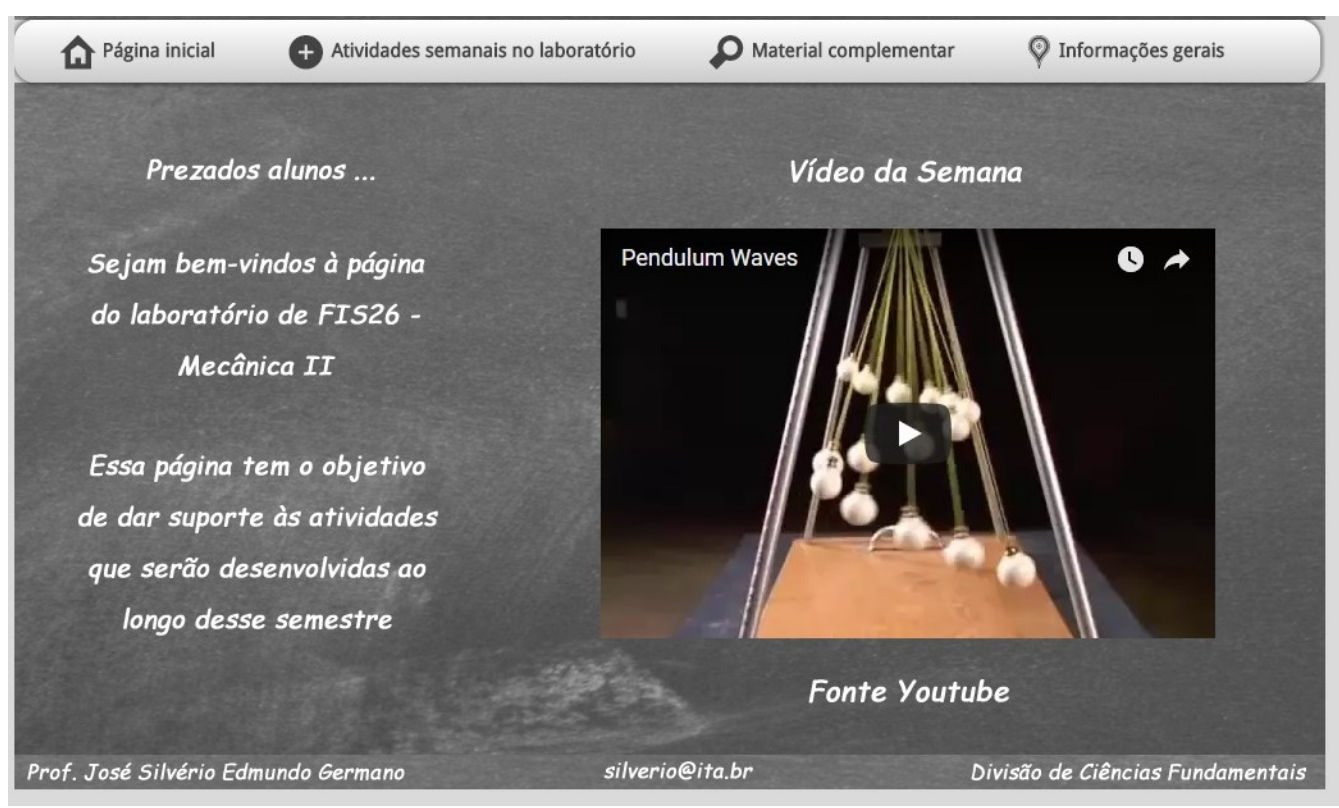

Figura 3 -Página inicial do site do laboratório FIS26. Fonte: O autor

O site possui conteúdo digital e uma gama de artigos com propostas de atividades PBL Problem Based Learning (Aprendizagem Baseada em Projetos). Além de contribuir com o material instrutivo o site possui informações relevantes como e-mail de professores, material para confecção de relatório (Word e PDF) e notebooks do software Mathematica $\AA$ para criar tabelas, gráficos, erros entre outras ações indispensáveis no laboratório de física.

\subsection{Maletas com Experimentos}

A biblioteca de experimentos é baseada num projeto da universidade canadense Athabasca. Esta universidade realiza desde o ano 2000 a disciplina de laboratório de física com o formato à distância, chamado de HomeLabs.

Os HomeLabs são kits de materiais para os estudantes realizarem as atividades em suas casas com um tutorial para auxiliar no desenvolvimento dos projetos[2]. Dentro dessa perspectiva, no $1^{\circ}$ semestre de 2017 realizamos um piloto com o material do laboratório de física criando uma caixa com conteúdo básico para realizar o experimento no H8. O kit montado para a prática de Oscilações segue na integra abaixo.

[2]

Acessado

em

20-12-17

http://science.athabascau.ca/Labs/documents/PHYS200_Lab_Manual_v2.3.pdf 


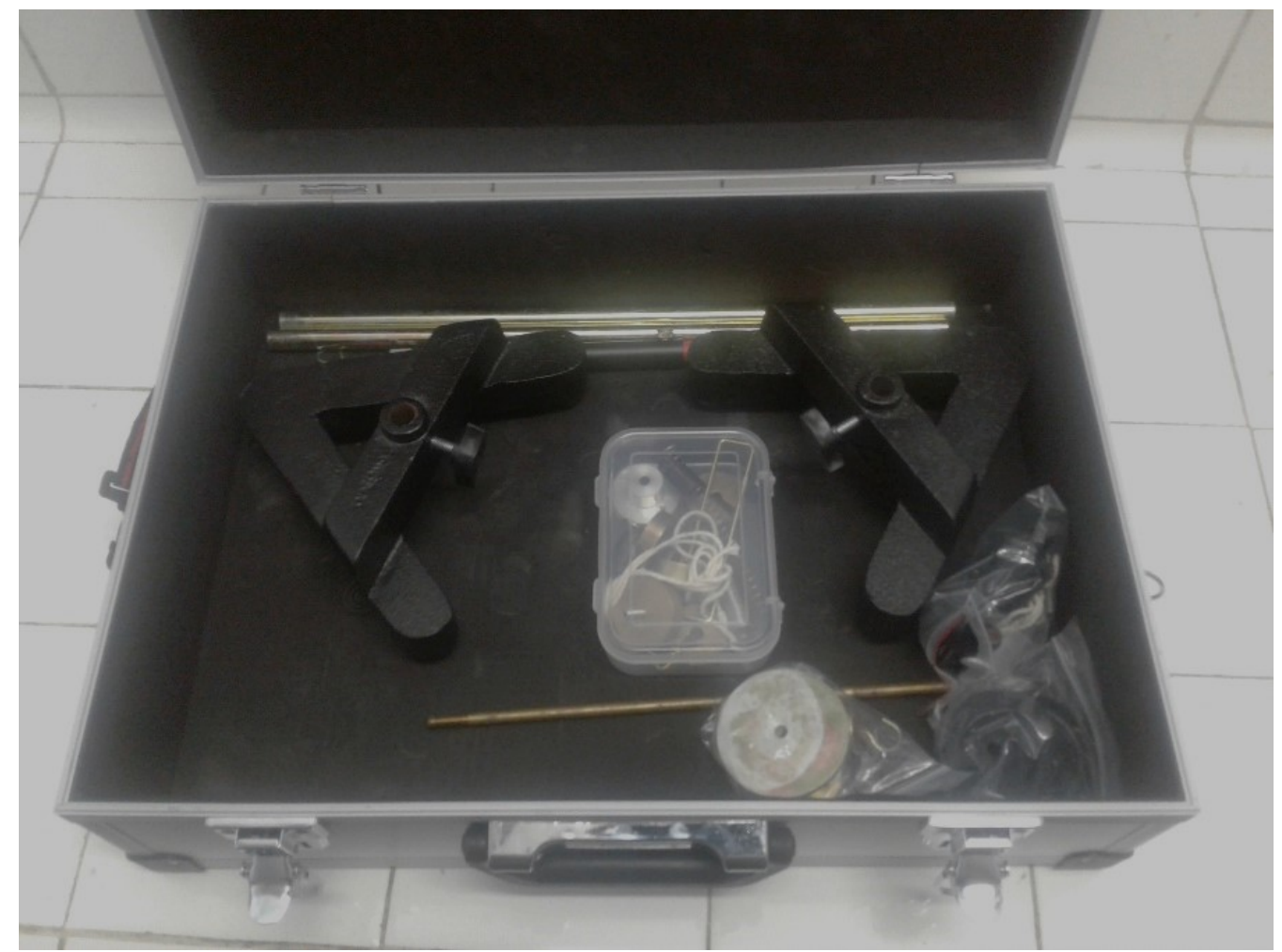

Figura 4 -Fotos do Kit Estruturas para o laboratório FIS26. Fonte: O autor

Para auxiliá-los foi criado um tutorial digital com videoaulas de como montar o experimento e manipular o material contido na caixa. Essas videoaulas foram distribuídas aos grupos para assistirem no H8. A página inicial desse material digital segue disponível abaixo:

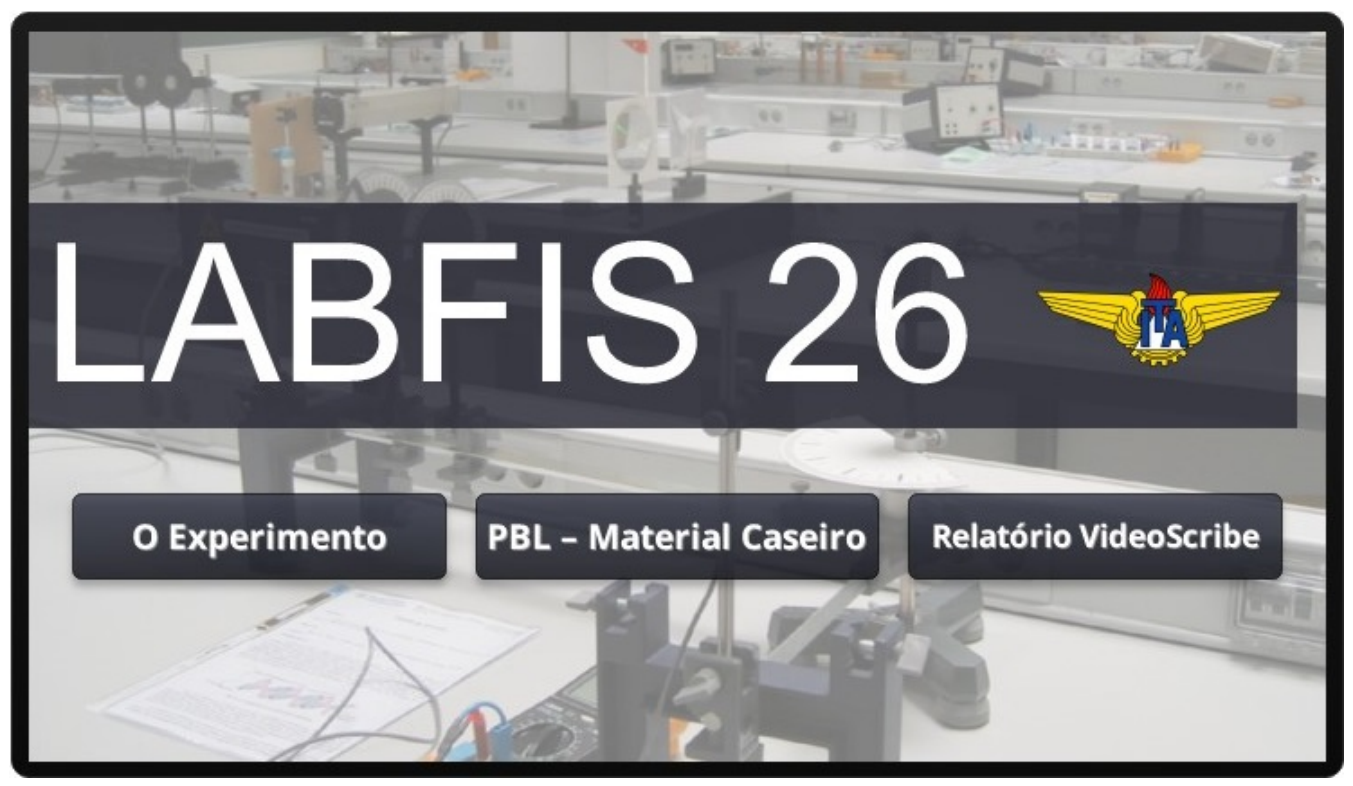

Figura 5 - Página inicial do material digital instrutivo do laboratório LABFIS26 disponível no sítio www.laboratorioremoto.com.br/eco/ead. Fonte: $O$ autor 


\section{Relatórios em vídeo}

Um dos resultados apresentados foram os relatórios em formato de vídeo.

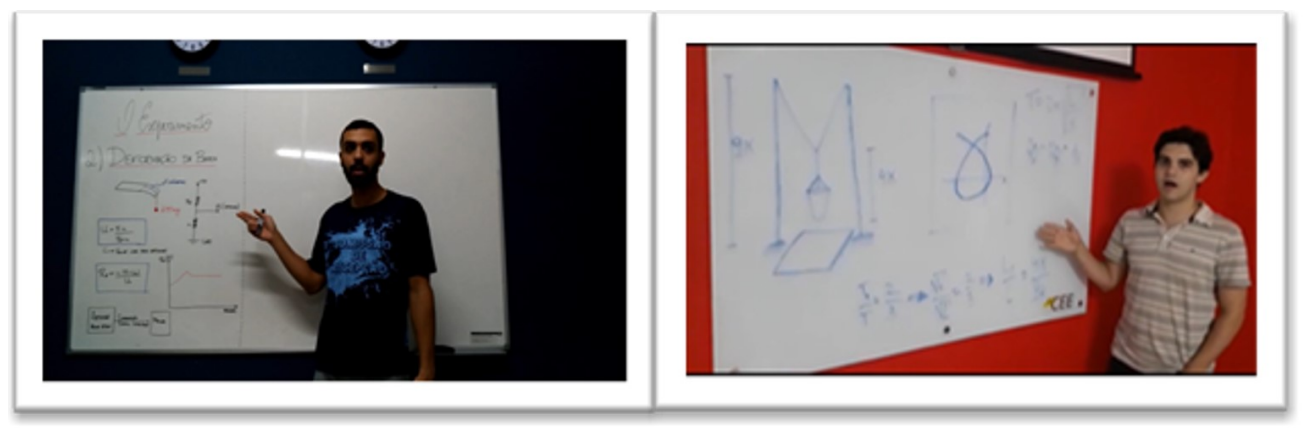

Figura 6 - Relatório dos alunos apresentando o problema em vídeo. Fonte: O autor

Salientamos que o trabalho com as tecnologias digitais pode tornar o processo de ensino e aprendizagem ainda mais atrativo, tanto para os alunos como para os professores, afinal isto possibilita a interdisciplinaridade dentro do curso de Engenharia, contribuindo para aumentar o entusiasmo pela aprendizagem.

Como apontou VENERAL et al (2017) as metodologias ativas, onde os estudantes são protagonistas permitem no ambiente EAD com que eles sejam autônomos do processo e ainda fiquem motivados para a realização, sendo uma metodologia nesse sentido.

\section{Resultados e Conclusões}

A avaliação da disciplina está em desenvolvimento. Um questionário dividido em seis partes (sobre a biblioteca, sobre o site da disciplina, sobre a plataforma google, sobre os professores e tutores, sobre as videoaulas, sobre os kits experimentais) foi aplicado aos participantes. Até o encerramento do prazo de submissão de artigos alguns estudantes responderam, desta forma temos adiante uma visão parcial da avaliação dos estudantes. 
A partir do material físico contido nas maletas. Qual a sua opinião do ponto de vista dos recursos. A quantidade de material disponível foi suficiente para a montagem experimental?

Como você classificaria a interação com os professores que estavam a frente do piloto "Biblioteca de experimentos" 6 respostas

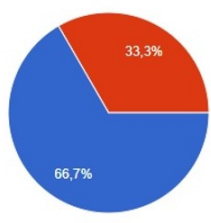

A respeito dos tutoriais em vídeo sobre o relatório em vídeo (VIDEOSCRIBE), no formato em que foram apresentados e disponibilizados eles foram suficientes e eficientes?

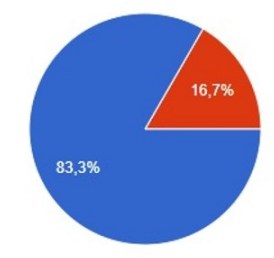

$$
\begin{aligned}
& \text { - ÓtIMO } \\
& \text { BOM } \\
& \text { REGULAR } \\
& \text { FRACO } \\
& \text { - NULO }
\end{aligned}
$$

Figura 7 - Gráfico parcial de avaliação feita pelos estudantes que participaram do projeto. Fonte: $\mathrm{O}$ autor

A partir da avaliação apresentada na figura 7 podemos avaliar alguns pontos positivos e negativos:

Os aspectos positivos podem ser destacados como o desenvolvimento de material instrucional para o ensino a distância do laboratório de física na plataforma Classroom para uma possível expansão dos cursos de engenharia do ITA.

Os kits ficarão como bens duráveis para o laboratório para futuras atividades e próximas turmas, bem como melhorias do material. A plataforma Google Classroom serviu como um elo entre os tutores e professores nas dúvidas dos estudantes e feedbacks de materiais solicitados como simulações e relatórios.

Existe uma importância muito relevante no processo de ensino aprendizagem o feedback como salienta PARDO et al (2017). Ademais, a partir dos feedbacks dos estudantes é possível melhorar os materiais didáticos mitigando futuras dúvidas.

Os aspectos negativos podemos pontuar a dificuldade de alguns materiais que não constavam nas maletas, sendo necessário visitas ao laboratório ou até mesmo adaptações com materiais caseiros. Houve dificuldade de acesso ao portal de videoaulas devido à queda do servidor, o problema foi solucionado com o upload dos 
arquivos em vídeo para uma plataforma livre na nuvem. Outra limitação encontrada foi no Google Drive como repositório de arquivos. Ao final do $2^{\circ}$ mês de atividades, este já se encontrava no limite. Todavia, um backup e a limpeza do mesmo resolveu 0 problema.

\section{Bibliografia}

AGUIAR, C. E. e LAUDARES, F. (2001). Aquisição de dados usando logo e a porta de jogos do PC. Revista Brasileira de Ensino e Física, São Paulo, 23 (4), 371-380.

Arduino (2005) Página oficial da Plataforma Arduino. Disponível em: Acesso em: 16 janeiro. 2018.

CAVALCANTE, Marisa Almeida, e TAVOLARO, Cristiane R. C. Projete Você Mesmo Experim entos Assistidos por Computador: Construindo Sensores e Analisando Dados. Revista Brasileira de Ensino de Física vol. 22, n. 3 (421-425). São Paulo. 2000

LAUDARES, F.A.L, et al. Instrumentação para Ensino de Física da UFRuralRJ: experiências docentes para a introdução tecnológica. Revista de Formación e Innovación Educativa Universitaria. Vol. 7, № 1, 51-58 (2014)

MOREIRA, M. A. Uma abordagem cognitivista ao ensino da Física. Porto Alegre: Editora de Universidade, 2009.

MOREIRA, M. A. e Gonçalves, E. S. Laboratório estruturado versus não estruturado: um estudo comparativo em um curso individualizado. Revista Brasileira de Física, São Paulo, 10 (2), 1980.

PARDO. J.M. et al. Engenharia na educação a distância: o potencial de contribuição do feedback no processo de aprendizado. ABED - Maio 2017

VENERAL, D.C et al. Metodologias ativas nos cursos de engenharia ead: tecnologias aplicadas na busca da inovação e daqualidade de ensino - ABED Maio 2017 